\title{
WPMVP 2018
}

\section{Proceedings of the 2018 4th Workshop on Programming Models for SIMD/Vector Processing}

\author{
Co-located with: \\ PPoPP'18 \\ Vienna, Austria \\ March 132018
}




\title{
The Association for Computing Machinery \\ 2 Penn Plaza, Suite 701 \\ New York New York 10121-0701
}

\begin{abstract}
ACM COPYRIGHT NOTICE. Copyright (C) 2007 by the Association for Computing Machinery, Inc. Permission to make digital or hard copies of part or all of this work for personal or classroom use is granted without fee provided that copies are not made or distributed for profit or commercial advantage and that copies bear this notice and the full citation on the first page. Copyrights for components of this work owned by others than ACM must be honored. Abstracting with credit is permitted. To copy otherwise, to republish, to post on servers, or to redistribute to lists, requires prior specific permission and/or a fee. Request permissions from Publications Dept., ACM, Inc., fax +1 (212) 8690481,

or permissions@acm.org.
\end{abstract}

For other copying of articles that carry a code at the bottom of the first or last page, copying is permitted provided that the per-copy fee indicated in the code is paid through the Copyright Clearance Center, 222 Rosewood Drive, Danvers, MA 01923, +1-978-750-8400, +1-978-750-4470 (fax).

Notice to Past Authors of ACM-Published Articles

ACM intends to create a complete electronic archive of all articles and/or other material previously published by ACM. If you have written a work that was previously published by ACM in any journal or conference proceedings prior to 1978, or any SIG Newsletter at any time, and you do NOT want this work to appear in the ACM Digital Library, please inform permissions@acm.org, stating the title of the work, the author(s), and where and when published.

ACM ISBN: 978-1-4503-5646-6 


\section{Program Committee}

- Jan Eitzinger (RRZE, University Erlangen-Nuremberg, Germany)

- Gabriel Tanase (IBM Research, Austin, TX, USA)

- James Brodman (Intel, USA)

- Sebastian Hack (University Saarland, Germany)

- Paul Kelly (Imperial College London, UK)

- Franz Franchetti ( CMU, USA )

- Lionel Lacassagne (University Paris 6, France)

- Daniel Etiemble (University Paris 11, France)

- Michael Klemm (Intel, Germany)

- Jose Moreira ( IBM Research, TJ Watson, NY, USA )

- Marat Dukhan (Georgia Tech, USA now Facebook)

- Etienne Walter (Atos, France)

- Pablo de Oliveira Castro (UVSQ, Versailles, France)

- Peng Wu (Huawei Research Labs, USA)

- Gabriele Keller (University of New South Wales, Australia)

- Fernanda Foertter (Oak Ridge National Lab, US)

- Sandra Wienke (RWTH Aachen, Germany)

- Roxana Rusitoru (ARM, UK)

\section{Organizing Committee}

- Jan Eitzinger (RRZE, University Erlangen-Nuremberg, Germany)

- James Brodman (Intel) 


\section{Contents}

\section{Small SIMD Matrices for CERN High Throughput Computing}

Florian Lemaitre, Benjamin Couturier and Lionel Lacassagne

2 MIPP: a Portable C++ SIMD Wrapper and its use for Error Correction Coding in 5G Standard

Adrien Cassagne, Olivier Aumage, Denis Barthou, Camille Leroux and Christophe Jégo

\section{SIMDization of Small Tensor Multiplication Kernels for Wide SIMD} Vector Processors

Christopher Rodrigues, Amarin Phaosawasdi and Peng Wu

4 Usuba, Optimizing \& Trustworthy Bitslicing Compiler

Darius Mercadier, Pierre-Évariste Dagand, Lionel Lacassagne and Gilles Muller

5 Investigating automatic vectorization for real-time 3D scene understanding

Alexandru Nica, Emanuele Vespa, Pablo González de Aledo and Paul H J Kelly

6 Ikra-Cpp: A C++/CUDA DSL for Object-Oriented Programming with Structure-of-Arrays Layout

Matthias Springer and Hidehiko Masuhara

7 A Data Layout Transformation for Vectorizing Compilers

Matthias Springer and Hidehiko Masuhara

8 A Data Layout Transformation for Vectorizing Compilers

Arsène Pérard-Gayot, Richard Membarth, Philipp Slusallek,

Simon Moll, Roland Leißa and Sebastian Hack 